\title{
The Budyko and complementary relationships in an idealized model of large-scale land-atmosphere coupling
}

\author{
B. R. Lintner ${ }^{1}$, P. Gentine ${ }^{2}$, K. L. Findell ${ }^{3}$, and G. D. Salvucci ${ }^{4}$ \\ ${ }^{1}$ Department of Environmental Sciences, Rutgers, The State University of New Jersey, New Brunswick, NJ, USA \\ ${ }^{2}$ Department of Earth and Environmental Engineering and Earth Institute, Columbia University, New York, NY, USA \\ ${ }^{3}$ Geophysical Fluid Dynamics Laboratory, Princeton, NJ, USA \\ ${ }^{4}$ Department of Earth and Environment, Boston University, Boston, MA, USA \\ Correspondence to: B. R. Lintner (lintner@envsci.rutgers.edu)
}

Received: 15 May 2014 - Published in Hydrol. Earth Syst. Sci. Discuss.: 7 August 2014

Revised: 18 February 2015 - Accepted: 23 February 2015 - Published: 4 May 2015

\begin{abstract}
Two well-known relationships in hydrology and hydrometeorology, the Budyko and complementary relationships, are examined within an idealized prototype representing the physics of large-scale land-atmosphere coupling developed in prior work. These relationships are shown to hold on long (climatologic) timescales because of the tight coupling that exists between precipitation, atmospheric radiation, moisture convergence and advection. The slope of the $\mathrm{CR}$ is shown to be dependent on the Clausius-Clapeyron relationship between saturation-specific humidity and temperature, with important implications for the continental hydrologic cycle in a warming climate; e.g., one consequence of this dependence is that the CR may be expected to become more asymmetric with warming, as higher values of the slope imply a larger change in potential evaporation for a given change in evapotranspiration. In addition, the transparent physics of the prototype permits diagnosis of the sensitivity of the Budyko and complementary relationships to various atmospheric and land surface processes. Here, the impacts of anthropogenic influences, including large-scale irrigation and global warming, are assessed.
\end{abstract}

\section{Introduction}

Observations of the annual terrestrial surface water balance demonstrate a tight and relatively simple functional dependence of evapotranspiration on the atmospheric water supply (precipitation) and demand (potential evaporation) at the surface (Budyko, 1961; Porporato et al., 2004; Roderick and
Farquahr, 2011; Williams et al., 2012; Zanardo et al., 2012). Such observations have stimulated development of simplified analytical formulations of the annual water balance (Budyko, 1961; Lettau, 1969; Eagleson, 1978a, b, c; Fu, 1981; Milly, 1994; Porporato et al., 2004; Harman et al., 2011; Sivapalan et al., 2011). Budyko (1961, 1974) developed arguably the most well-known approach for characterizing catchment-scale hydrologic balances on long (decadal and greater) timescales. By hypothesizing limitations on land surface evapotranspiration imposed by the availability of water and energy, Budyko introduced a relationship of the form

$\frac{E}{P}=B\left(\frac{E_{\mathrm{p}}}{P}\right)$,

where $E, P$, and $E_{\mathrm{p}}$ are evapotranspiration, potential evapotranspiration, and precipitation, respectively. The ratio $E_{\mathrm{p}} / P$ is commonly known as the dryness or aridity index $(\phi)$, and hereafter we denote the ratio $E / P$ as $B(\phi)$, i.e., the Budyko curve. Empirical forms of $B(\phi)$ have been obtained by fitting to observed $E, P$, and $E_{\mathrm{p}}$ with $E$ typically estimated as the residual of precipitation and basin-scale streamflow (Budyko, 1961, 1974). $B(\phi)$ appears to be rather stable across different regions and hydroclimatic environments (Potter et al., 2005; Yang et al., 2007; Gentine et al., 2012).

The last two decades have seen renewed interest in the Budyko curve (e.g., Milly, 1994; Koster and Suarez, 1999; Milly and Dunne, 2002; Porporato et al., 2004; Potter et al., 2005; Donohue et al., 2007; Yang et al., 2008; Gerrits et al., 2009; Gentine et al., 2012; Istanbulluoglu et al., 2012; Williams et al., 2012). Many studies have employed sim- 
plified models of the surface and groundwater moisture response to precipitation forced by $E_{\mathrm{p}}$ to investigate the robustness of the Budyko curve in different catchments. Milly (1994) and Porporato et al. (2004), in particular, investigated the response of the annual water balance to changes in the characteristics of potential evaporation and precipitation intensity and frequency, yielding new insights into the sensitivity of the annual water balance to changes in surface energy and water forcing, all other factors, e.g., vegetation characteristics, soil, and topography, remaining constant. However, apart from a few studies investigating the catchment co-evolution and adaptation of vegetation to the water and energy forcing (Troch et al., 2009; Sivapalan et al., 2011; Gentine et al., 2012), a direct explanation of the stability and widespread applicability of the Budyko relationship across a range of conditions remains elusive.

In the Budyko framework, as in most hydrologic models, $E_{\mathrm{p}}$ is prescribed as a forcing, which is thought to be independent of the surface. Nonetheless, $E$ and $E_{\mathrm{p}}$ have been hypothesized to be inversely related to one another (Bouchet, 1963; Morton, 1983; Brutsaert and Stricker, 1979; Hobbins et al., 2001) on daily to annual timescales. In fact, the coupling between $E$ and $E_{\mathrm{p}}$ provides the basis for a foundational relationship in hydrometeorology: the complementary relationship, first introduced by Bouchet (1963) and Morton (1983). Mathematically, the complementary relationship (CR) can be expressed as

$E_{\mathrm{p}}+b E=(1+b) E_{\text {wet }}$.

In Eq. (2), $E_{\mathrm{p}}$ is potential evaporation and $E_{\mathrm{wet}}$ is the energylimited, wet surface equilibrium evapotranspiration. Bouchet (1963) assumed a value of 1 for the scale factor $b$, while Pettijohn and Salvucci (2009), hereafter PS09, report values in the range 3-6 based on numerical simulations of an evaporation pan in a drying environment. Since $E_{\mathrm{p}}$ cannot directly be measured, pan evaporation has often been used in lieu of potential evaporation using a pan correction factor (Bosman, 1987; Roderick and Farquahr, 2004; van Heerwaarden et al., 2010). Kahler and Brutsaert (2006) assumed that use of pan measurements in Eq. (2) may account for $b>1$ because a pan transmits heat, resulting in warmer water inside the pan relative to a larger free water body (e.g., lake) under similar ambient conditions.

Although several studies (Zhang et al., 2004; Ramirez et al., 2005; Szilagyi and Jozsa, 2009) have discussed possible links between the CR and the Budyko curve, to date a theoretical framework encompassing either or both of these relationships is still absent. Milly (1994) underscores the lack of physical understanding for why the Budyko curve deviates from its water- and energy-limited asymptotes, while Ramirez et al. (2005) suggest that, apart from heuristic arguments or under restrictive conditions, no general proof of the $\mathrm{CR}$ is available. Moreover, questions remain about the applicability and validity of the Budyko and complementary relationships across different spatial and temporal scales.
Here, we note that observational data confirm the CR holds on daily to annual timescales (Bouchet, 1963; Kahler and Brutsaert, 2006) and across local to regional spatial scales (Granger, 1989; Szilagyi, 2001; Crago and Crowley, 2005; PS09; van Heerwaarden et al., 2010), which is usually understood in terms of the diurnal-scale interactions of the boundary layer with the surface, although questions have been raised about some of the assumptions inherent in these approaches. Indeed, as PS09 note, some explanations for the CR have relied on contradictory assumptions. For example, the derivation of Szilagyi (2001) assumes that as $E$ decreases, the surface temperature of the evaporation pan remains constant while the overlying near surface-specific humidity decreases, increasing the vapor deficit and thus the evaporation rate over the pan. By contrast, in Granger (1989), surface temperature is assumed to increase while specific humidity remains constant, thus also increasing the humidity gradient and pan evaporation rate. L'homme and Guilioni (2006) have questioned the physical validity and applicability of these assumptions.

In the present study, we make use of a semi-analytic, idealized prototype of large-scale land-atmosphere coupling developed in prior work (Lintner et al., 2013) to derive the Budyko and complementary relationships. Our approach differs from prior analyses in that (i) it is implicitly large-scale and relevant on climatic timescales, and (ii) convergence, advection, precipitation and atmospheric radiation are treated implicitly rather than as exogenous forcing. The latter renders the atmospheric and surface moisture interactive and tightly coupled vertically but also horizontally - through the (nonlocal) effects of moisture advection and convergence. Several studies have pointed out that such tight coupling between radiation, larger-scale circulation and the local surface energy budget is key to understanding locally observed landatmosphere interactions (Betts et al., 1996, 2003, 2014; Betts and Viterbo, 2005; Betts, 2007). The analytic simplicity of the idealized prototype facilitates straightforward diagnosis of factors influencing the large-scale coupling, as highlighted in Lintner et al. (2013).

A key motivation for this study is consideration of how the continental hydrologic cycle, and more precisely how the behavior reflected in the Budyko curve and CR, may respond to anthropogenic influences. Indeed, the projected response of the terrestrial hydrologic cycle to various climate change mechanisms in models remains subject to large uncertainties (Sherwood and $\mathrm{Fu}, 2014$ ). Emergent behaviors such as the Budyko and complementary relationships may provide useful constraints on such uncertainties. For example, Brutsaert and Parlange (1998) have suggested that the CR may explain the apparent paradox between observed downward trends in pan evapotranspiration over the late twentieth century, and anticipated increases in evaporation resulting from a more intense hydrologic cycle in a warming atmosphere.

The paper is organized as follows. After providing a brief review of the prototype assumptions and governing equations 
(Sect. 2), we analyze the generalized Budyko and complementary relationships within our prototype (Sect. 3 ) and consider the physical parameters and processes impacting these relationships (Sect. 4). Here, we are interested in examining the behavior across a range of hydroclimatic states; in what follows, we use the term "prototype transect" to refer to this range. This may be viewed as representing either a spatial sampling of states across a climatological gradient in soil moisture at a fixed point in time or a temporal sampling (as under the seasonal evolution) at a fixed point in space. In Sect. 5, we examine how anthropogenic influences such as global warming and large-scale irrigation affect these relationships.

\section{Overview of the idealized land-atmosphere coupling prototype}

In prior work (Lintner et al., 2013), we developed a semianalytic prototype for land-atmosphere coupling. This prototype describes the coupling at spatial scales for which both local (evapotranspiration) and nonlocal processes (horizontal moisture advection and convergence) may be important to the water cycle budget. We consider steady-state conditions, corresponding to the climatological state of the hydrologic cycle. Although the steady-state assumption clearly limits the applicability of our model in the presence of important time-dependent processes operating in the climate system, we again note that the CR has been observed to hold across a range of timescales. Similarly, Budyko curves have been estimated from yearly mean observations (Budyko, 1974; Gentine et al., 2012).

The atmospheric component of this prototype is based on vertically integrated tropospheric temperature and moisture equations from the Quasi-equilibrium Tropical Circulation Model (QTCM; Neelin and Zeng, 2000; Zeng et al., 2000), an intermediate level complexity model for the tropical atmosphere:

$$
\begin{array}{r}
-\mathrm{Ms} \nabla_{\mathrm{H}} \cdot \boldsymbol{v}+P+R_{\mathrm{net}}+H=0, \\
\mathrm{Mq} \nabla_{\mathrm{H}} \cdot \boldsymbol{v}-P+E-\boldsymbol{v}_{\mathrm{q}} \cdot \nabla_{\mathrm{H}} q=0,
\end{array}
$$

where $\nabla_{\mathrm{H}}$ is the horizontal gradient operator; $R_{\text {net }}$ is the net column (top of the atmosphere minus surface) radiative heating; Ms and Mq are the dry static stability and moisture stratification and $\nabla_{\mathrm{H}} \cdot \boldsymbol{v}$ is signed positive for low-level convergence; and $\boldsymbol{v}_{\mathrm{q}}$ is the vertically averaged horizontal wind vector weighted by the moisture vertical structure assumed in QTCM1. (Note that baseline values for parameters such as Ms and Mq are given in Lintner et al., 2013, and references therein. Table 1 summarizes the parameter values most relevant to the present study.) The term $P$ in Eqs. (3) and (4) represents the net convective (condensational) heating and drying, respectively; the negative sign in Eq. (4) indicates that precipitation is a net sink of vertically averaged tropospheric moisture. For the temperature Eq. (3), we have neglected horizontal temperature gradients following the weak temperature gradient assumption (Sobel and Bretherton, 2000; Sobel et al., 2001). Note that all terms appearing in Eqs. (3) and (4) are implicitly scaled to units of mm day ${ }^{-1}$ by absorbing constants such as (specific) heat capacity, latent heat of fusion, and column mass per unit area $\Delta p / g$, where $\Delta p$ is the tropospheric pressure depth.

A steady balanced surface energy flux constraint, in which the annual-mean ground surface heat flux is neglected, reads

$R_{\text {surf }}-E-H=0$,

where the net surface radiative heating, $R_{\text {surf }}$, is signed positive downward.

In Lintner et al. (2013), we consider tropospheric temperature $(T)$ as prescribed and solve the system of Eqs. (3)-(5) for $q, \nabla_{\mathrm{H}} \cdot \boldsymbol{v}$, and surface temperature $T_{\mathrm{S}}$ for prescribed largescale advection. A closed-form, self-consistent solution can be obtained by invoking the steady-state soil moisture budget:

$P-E-Q_{\text {runoff }}=0$,

where $Q_{\text {runoff }}$ is the net runoff. For analytic simplicity, we assume a simple bucket model, with an evaporative efficiency, $\beta=\frac{E}{E_{\mathrm{p}}}$, for which we assume a simple linear relationship $\beta=w$ (Porporato et al., 2001, 2004), where $w$ is the dimensionless soil moisture (actual soil moisture normalized by a holding capacity). $Q_{\text {runoff }}$ is represented as the precipitation rate times a power law of soil moisture, $Q_{\text {runoff }}=P w^{\eta}$ (Kirchner, 2009). The baseline power law scaling exponent is $\eta=4$, the value used in Lintner et al. (2013). The suitability of invoking a single moisture storage variable to represent both basin-scale evaporative efficiency and runoff has recently been demonstrated at nine watersheds containing Ameriflux eddy covariance measurements of evaporation and gauged streamflow (Tuttle and Salvucci, 2012).

For analytic simplicity, we consider linearized radiative and surface turbulent fluxes of the form

$$
\begin{aligned}
H & =H_{0}+\varepsilon_{H}\left(T_{\mathrm{s}} s-a_{1 \mathrm{~s}} T\right) \\
E & =\beta\left[E_{\mathrm{p}_{0}}+\varepsilon_{\mathrm{H}}\left(\gamma T_{\mathrm{s}}-b_{1 \mathrm{~s}} q\right)\right. \\
R_{x} & =R_{x 0}+\varepsilon_{T_{\mathrm{s}}}^{R_{x}} T_{\mathrm{s}}+\varepsilon_{T}^{R_{x}} T+\varepsilon_{\mathrm{q}}^{R_{x}} q+c_{x} P
\end{aligned}
$$

Quantities with subscript " 0 " denote the values about which the fluxes are linearized, with coefficients $\varepsilon$ representing the linear sensitivity of fluxes to $T, q$, and $T \mathrm{~s}$. The scale factors $a_{1 \mathrm{~s}}$ and $b_{1 \mathrm{~s}}$ relate vertically averaged temperature and moisture to near-surface values appropriate for computation of surface bulk turbulent fluxes. The coefficient $\gamma=\frac{\mathrm{d} q^{*}}{\mathrm{~d} T}$ is the slope of the saturation-specific humidity $\left(q^{*}\right)$ with respect to temperature, as defined via the Clausius-Clapeyron equation. Note that, in our usage, $q$ (or $q^{*}$ ) is implicitly scaled to units of temperature $(\mathrm{K})$ via absorption of the psychrometric constant; thus, $\gamma$ is dimensionless. The radiative fluxes are calculated at the top-of-the-atmosphere and the surface $(x=$ toa 
Table 1. Parameter definitions and values in the baseline land-atmosphere coupling prototype.

\begin{tabular}{lll}
\hline Parameter & Definition & Value \\
\hline$a_{1 \mathrm{~s}}$ & Weighting factor for surface temperature & 0.30 \\
$\alpha$ & Priestley-Taylor coefficient & 1.26 \\
$b_{1 \mathrm{~s}}$ & Weighting factor for surface moisture & 1.15 \\
$b$ & Complementary relationship scale factor & - \\
$c_{\text {surf }}$ & Surface cloud longwave forcing coefficient & 0.18 \\
$\gamma$ & Dimensionless slope of Clausius-Clapeyron relationship & 3.5 \\
$\varepsilon_{\mathrm{H}}$ & Linearized surface turbulent flux scaling coefficient & $42 \mathrm{~mm} \mathrm{day}^{-1} \mathrm{~K}^{-1}$ \\
$\eta$ & Runoff power law scaling exponent & 4 \\
$\tau_{\mathrm{c}}$ & Convective adjustment timescale & $2 \mathrm{~h}$ \\
\hline
\end{tabular}

and $x=$ surf), and the coefficients $c_{x}$ are cloud-radiative forcing sensitivities, with cloud-radiative fluxes assumed to be linearly proportional to the precipitation rate. Precipitation (convective heating in Eq. 3 or convective drying in Eq. 4) is formulated in terms of a Betts and Miller (1986) type relaxation scheme:

$P=\max \left[\varepsilon_{\mathrm{c}}\left(q-q_{\mathrm{c}}(T)\right), 0\right]$.

Here, $q_{\mathrm{c}}(T)$ is a temperature-dependent moisture threshold and $\varepsilon_{\mathrm{c}}$ is the convective adjustment rate coefficient (inversely related to the timescale for convective adjustment $\tau_{\mathrm{c}}$ ).

\section{Overview of the baseline relationships}

\subsection{Complementary relationship}

Figure 1a illustrates the functional relationships between soil moisture and $E, P$, and $E_{\mathrm{p}}$ of the prototype. The general response of $E$ and $E_{\mathrm{p}}$ with increasing soil moisture, namely $E_{\mathrm{p}}$ decreasing and $E$ (generally) increasing, is consistent with the CR (Eq. 2). $E_{\mathrm{p}}$ relates to $w$ through the deficit between ambient and saturation-specific humidity at the surface (Lintner et al., 2013): the deficit decreases with increasing soil moisture since $q$ increases and $T_{\mathrm{s}}$ decreases. Figure 2 depicts the results of the prototype against $E$ and $E_{\mathrm{p}}$ observations from the Little Washita River basin near Chickasha, Oklahoma (see Kahler and Brutsaert, 2006, for a full description of the data set). Here, $E_{\mathrm{p}}$ was obtained directly from pan evaporation measurements with a correction factor and $E$ was measured using the Bowen ratio (EBBR) technique. $E$ and $E_{\mathrm{p}}$ are presented in dimensionless units by dividing by the Priestly and Taylor (1972) evaporation, i.e., $E_{\mathrm{wet}}=\alpha \frac{\gamma}{1+\gamma} R_{\text {surf }}$, where $\alpha$ is a correction factor with an estimated value of $\sim 1.26$. The $\mathrm{CR}$ from the prototype shows a qualitative, and arguably even quantitative, correspondence to both observational data sets. Of course, we should point out that the prototype was not explicitly tuned to represent the hydroclimate of these locations, and as such, any quantitative correspondence may be coincidental. Moreover, the scatter inherent in the observations would permit a range of plausible complementary relationships.

A slight decrease in $E$ is observed for $w \gtrsim 0.7$ (see the gray curve in Fig. 1a). To our knowledge, such a decrease has not been previously investigated, even though it appears in in situ measurements (Kahler and Brutsaert, 2006; PS09), as evident in Fig. 2. The decrease in both $E$ and $E_{\mathrm{p}}$ arises from the monotonic decrease in $E_{\mathrm{p}}\left(\frac{\partial E_{\mathrm{p}}}{\partial w}<0\right)$ at large soil moisture, as pointed out by Lintner et al. (2013). Indeed, in the prototype, increasing soil moisture is a consequence of increasing precipitation, with the latter progressively balanced by higher moisture convergence (cf. Fig. 3 of Lintner et al., 2013). Increasing moisture convergence is associated with increasing (low-level) humidity, which reduces the surface vapor pressure deficit, thereby reducing $E_{\mathrm{p}}$. Overall, the moisture balance at large soil moisture values implies a greater role for nonlocal processes. On the other hand, at very low soil moisture values, mean $P$ is mostly balanced by $E$, resulting in a tight link among $E, E_{\mathrm{p}}$, and $w$. This explains the success of local coupled land-boundary layer models (Bouchet, 1963; van Heerwaarden et al., 2010) in representing the drier regime of the CR.

In prior studies of the CR, a quantity $E_{\text {wet }}$ was introduced to denote the point of convergence of $E$ and $E_{\mathrm{p}}$ under unlimited soil moisture (saturated surface) conditions, i.e., at high soil moisture values (see Eq. 2). Conventionally, $E_{\text {wet }}$ is assumed to represent equilibrium $E$ from a saturated surface when advection is minimal and is usually computed empirically following Priestly and Taylor (1972). While the prototype $E_{\mathrm{p}}$ does indeed converge toward $E$ as soil moisture increases, there is in fact no unique value of $E_{\text {wet }}$ because of the decline $E$ at high soil moisture.

As PS09 further note, plotting potential evapotranspiration and evapotranspiration against soil moisture (or a similar variable) may mask the linear nature of the CR. Thus, Fig. 1b depicts $E_{\mathrm{p}}$ directly as a function of $E$. In this case, the approximate linearity implied by Eq. (1) is found to hold over a large range of $E$ and $E_{\mathrm{p}}$ values. A linear regressive best fit to the $E_{\mathrm{p}}$ vs. $E$ relationship for $E<6 \mathrm{~mm} \mathrm{day}^{-1}$ yields a slope, i.e., the parameter $b$ in Eq. (1), of magnitude $\sim 3.8$. 

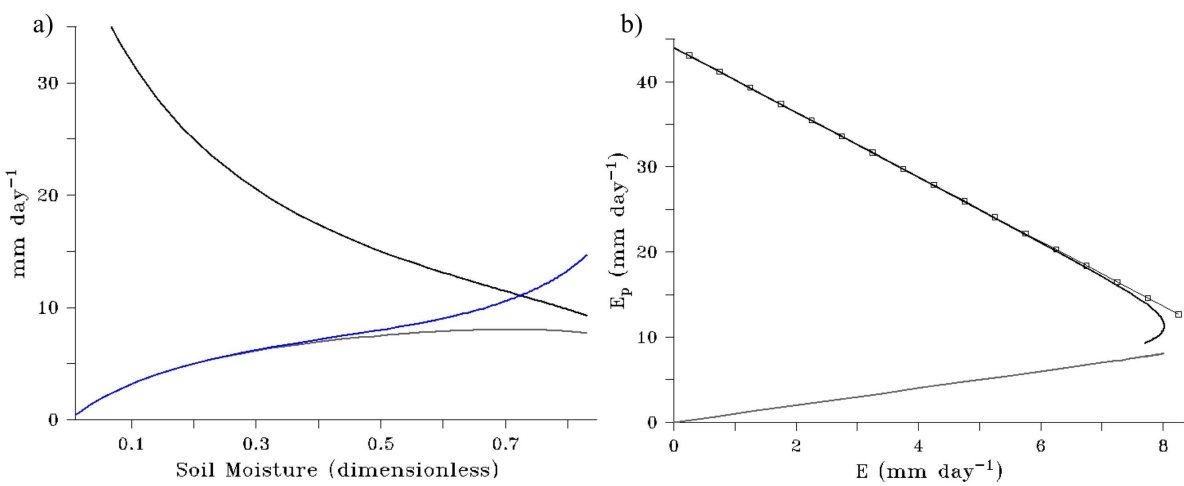

Figure 1. Complementary relationship in the baseline configuration. (a) Potential evapotranspiration $\left(E_{\mathrm{p}}\right.$; black), evapotranspiration $(E$; gray), and precipitation ( $P$; blue) as functions of soil moisture $(w)$. (b) $E_{\mathrm{p}}$ vs. $E$ (black) and the $1: 1$ line (gray). Also shown is the best fit linear regression of the $E_{\mathrm{p}}$ to $E$ relationship (squares).

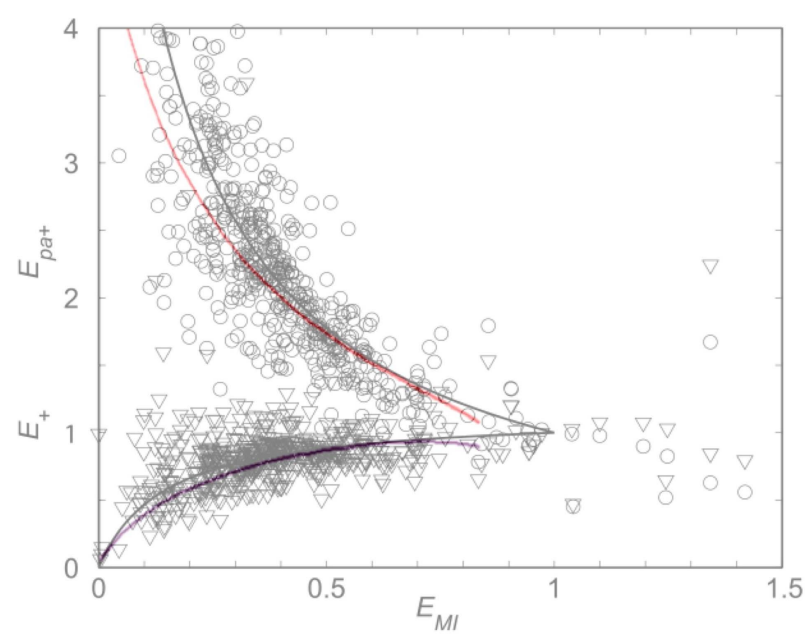

Figure 2. Baseline complementary relationship compared to Kahler and Brutsaert's observational data from the Little Washita River basin in Oklahoma, USA (cf. Fig. 5 in Kahler and Brutsaert, 2006). Symbols shown correspond to two different normalizations of the observations and gray lines to best fits through these points. The values along the abscissa, $E_{\mathrm{MI}}$, correspond to the ratio of actual to pan evaporation in Kahler and Brutsaert (2006) and are identical to soil moisture in the prototype. Prototype $E_{\mathrm{p}}$ and $E$ (red and purple curves, respective) have been normalized with respect to the value of $E_{\text {wet }}$ corresponding to the maximum value of $E$ along the transect.

This value of $b$ is quantitatively consistent with the estimates of Kahler and Brutsaert (2006), Szilagyi (2007), and PS09, and, unlike the original treatment of Bouchet (with $b=1$ ), implies a strongly asymmetric CR. The implied value of $b$ is close to $\gamma$, the dimensionless slope of the saturation-specific humidity curve, which is 3.5 in the baseline configuration; in fact, as we show in the parameter sensitivity analyses in Sect. $4.1, b$ varies predominantly with $\gamma$, which is consistent with the theoretical arguments presented in Granger (1989).
We can, in fact, derive an analytic expression for the CR for our land-atmosphere coupling prototype. We begin by subtracting $\gamma H$ from $E_{\mathrm{p}}$ and invoke the zero surface flux constraint to yield

$E_{\mathrm{p}}-\gamma H=E_{\mathrm{p}}+\gamma E-\gamma R_{\mathrm{s}}$.

Then, using the bulk formulae expressions for $E_{\mathrm{p}}$ and $H$, the left-hand side of Eq. (9) can be expanded as

$E_{\mathrm{p}}-\gamma H=\epsilon_{\mathrm{H}}\left(a_{1 \mathrm{~s}} \gamma T-b_{1 \mathrm{~s}} q\right)$.

Since precipitation rate $P=\epsilon_{\mathrm{c}}\left(q-q_{\mathrm{c}}(T)\right), q$ can be eliminated in favor of $P$, which upon rearranging the terms gives

$E_{\mathrm{p}}+\gamma E=\gamma R_{\mathrm{s}}-\frac{b_{1 \mathrm{~s}} \epsilon_{\mathrm{H}}}{\epsilon_{\mathrm{c}}} P+f(T)$.

In Eq. (11), $f(T)=\epsilon_{\mathrm{H}}(1+\gamma)^{-1}\left[a_{1 \mathrm{~s}} \gamma T-b_{1 \mathrm{~s}} q_{\mathrm{c}}(T)\right]$ is just a function of the (prescribed) tropospheric temperature, and is thus constant over the prototype transect.

Comparing Eq. (11) with Eq. (2), we find

$b=\gamma$

and

$E_{\mathrm{wet}}=(1+\gamma)^{-1}\left[\gamma R_{\mathrm{S}}+f(T)-\frac{b_{1 \mathrm{~s}} \epsilon_{\mathrm{H}}}{\epsilon_{\mathrm{c}}} P\right]$.

As discussed above, in prior work, $E_{\text {wet }}$ was defined using the relationship of Priestley and Taylor (1972). The term $(1+\gamma)^{-1} \gamma R_{\mathrm{S}}$ in Eq. (13) corresponds to the Priestley-Taylor formulation but with a coefficient of 1 in lieu of $\alpha$. It is worth noting that Kahler and Brutsaert's in situ observations imply a Priestley-Taylor coefficient in the range of $0.89-1.13$, which is in line with the value of 1 for the coefficient of $E_{\text {wet }}$ suggested by Eq. (13). The remaining terms in $E_{\text {wet }}$ are not explicitly represented in the Priestley-Taylor relationship $E_{\text {wet }}$, although this dependence may be implicitly captured 
through variation of the Priestley-Taylor coefficient. However, we note that the dependence of Eq. (13) on precipitation implies a negative feedback of $P$ on the $E_{\text {wet }}$, since higher tropospheric moisture is associated with higher precipitation, thereby decreasing vapor pressure deficit at the surface and suppressing $E_{\text {wet }}$. This is consistent with the decrease in $E$ at high soil moisture evident in Fig. 1a.

It is obvious that $E_{\text {wet }}$ as defined by Eq. (13) is not constant across the prototype transect, as it depends on surface radiative heating and precipitation. (In a more general model, variations in tropospheric temperature across the transect would also impact the value of $E_{\text {wet }}$.) Again, we point out that the Priestley-Taylor relationship only shows an explicit dependence on radiation (and the Clausius-Clapeyron slope). In addition to the negative feedback of precipitation on $E_{\text {wet }}$ through the vapor deficit, $R_{\text {surf }}$ itself also decreases as $P$ increases, owing to the negative cloud-radiative forcing associated with deep convective clouds (see Lintner et al., 2013). Related to the non-constancy of $E_{\text {wet }}$, we also note that the value of $b$ differs slightly from the value inferred from directly fitting to the linear portion of the $E_{\mathrm{p}}$ vs. $E$ curve in Fig. 1b.

\subsection{Budyko curve}

Within our prototype, the steady-state soil moisture Eq. (6) can be recast as

$$
B(\phi)=\left[1-Q_{\text {runoff }} / P\right] .
$$

For the simple case of a land surface bucket model with a runoff power law scaling exponent of $\eta=2$, and noting that soil moisture can be expressed as $w=\beta(w)=\frac{E}{E_{\mathrm{p}}}=\frac{B(\phi)}{\phi}$, Eq. (14) reduces to a quadratic equation in $B(\phi)$, with an analytic solution in terms of $\phi$ expressed as

$B(\phi)=\frac{\phi^{2}}{2}\left(\sqrt{1+\frac{4}{\phi^{2}}}-1\right)$.

Figure 3 illustrates the Budyko curves for the baseline configuration of the prototype $(\eta=4)$ and the analytic solution for $\eta=2$, with Budyko's well-known empirical formulation $B(\phi)=\sqrt{\phi \tanh \left(\phi^{-1}\right)\left(1-e^{-\phi}\right)}$ for comparison. Also depicted are the energy- and water-limited asymptotes. For the baseline configuration, $B(\phi)$ at intermediate values of the aridity index lies above the empirical Budyko fit, while the $\eta=2$ curve lies below. Variation in the shape of $B(\phi)$ with increasing values of $\eta$ is consistent with decreasing runoff for a given value of precipitation, which in turn necessitates shifting the surface water balance to favor $E$ over $Q_{\text {runoff. We }}$ point out that Eq. (15) possesses limiting behavior consistent with empirically derived estimates in prior studies (Budyko, 1961; Fu, 1981): thus, $B(\phi) \rightarrow 0$ as $\phi \rightarrow 0$ with a linear asymptote $B(\phi) \sim \phi$, while $B(\phi) \rightarrow 1$ as $\phi \rightarrow \infty$ with an asymptote $B(\phi) \sim 1-\phi^{-1}$. The limiting behavior of $B(\phi)$

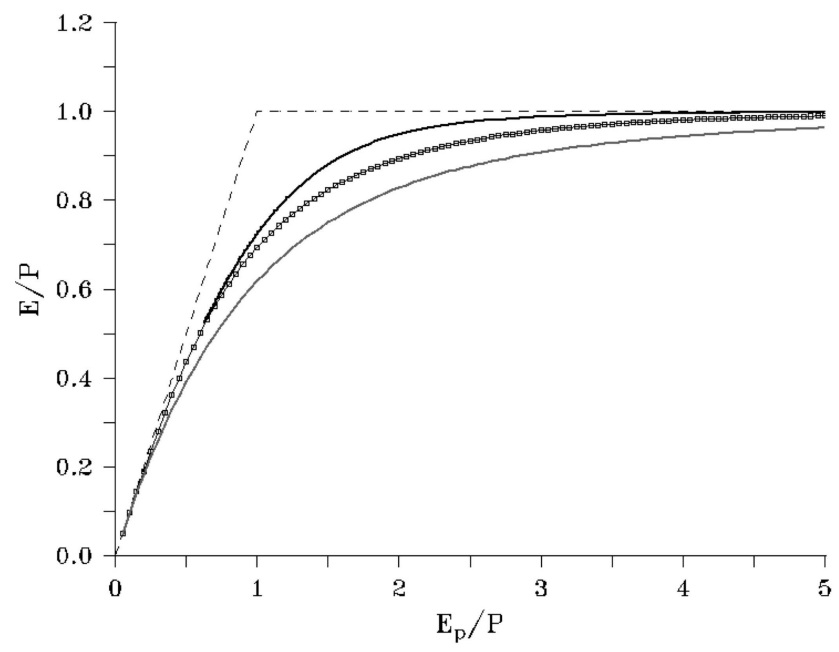

Figure 3. Prototype Budyko curves for the baseline prototype, i.e., $\eta=4$, in the formulation of runoff (thick black), for Eq. (15) for $\eta=2$ (gray), and Budyko's empirical formula (squares). The dashed lines are the energy- and water-limited asymptotes.

as $\phi \rightarrow 0$ further implies that $E \rightarrow E_{\mathrm{p}}$, which in turn necessitates $E_{\mathrm{p}} \rightarrow 0$ in this limit. In other words, the decline in $E$ at high soil moisture noted in Sect. 3.1 is also consistent with the Budyko curve.

\section{Parameter and process sensitivity}

\subsection{Parameter sensitivity}

We now explore how the CR depends on parameter values assumed in the prototype. In particular, we focus on how the implied slope of $E_{\mathrm{p}}$ vs. $E$ (e.g., the slope of the dashed black line in Fig. 1b) depends on a subset of four prototype parameters: the dimensionless slope of the saturation-specific humidity curve, $\gamma$; the surface drag coefficient, which is embedded in the turbulent flux scaling coefficient $\varepsilon_{\mathrm{H}}$; the surface cloud longwave forcing, $c_{\text {surf }}$; and the convective adjustment timescale, $\tau_{\mathrm{c}}$. Our consideration of $\gamma$ is motivated by its control on the Bowen ratio or, similarly, the evaporative fraction (Gentine et al., 2011), and thus effectively the relative variation of $q$ compared to $T_{\mathrm{s}}$. We note that, with global warming, the saturation-specific humidity is expected to increase and thereby modify precipitation and the hydrologic cycle (Held and Soden, 2006). The surface drag coefficient depends on surface roughness, which could account for some of the heterogeneity in the observed slope of $E_{\mathrm{p}}$ vs. $E$. The remaining two parameters, $c_{\text {surf }}$ and $\tau_{\mathrm{c}}$, are associated with two of the more uncertain aspects of current generation climate models, namely, the effect of clouds on radiation and the parameterization of deep convection, respectively. Although the representation of clouds and convective processes is grossly simplified in the prototype, we can view the parameter sensitivity 
to $c_{\text {surf }}$ and $\tau_{\mathrm{c}}$ as a guide for anticipating how uncertainty in analogs to these parameters contained in more complex climate models may be expected to influence the CR evident in these models.

Figure 4 illustrates the percentage variation of the CR slope relative to its baseline value $(\sim 3.8)$ as functions of percentage variations in each of the four sensitivity parameters. Each of the latter is varied uniformly over a range of $\pm 50 \%$ of the baseline values indicated in Table 1. It is immediately clear that the slope of the CR varies in a $1: 1$ manner with $\gamma$. On the other hand, for the remaining three parameters, the percentage change in the CR slope is typically an order of magnitude smaller. We point out the nonlinearity associated with changing the surface drag coefficient, as decreasing surface drag produces a proportionately larger reduction in the slope of the CR compared to increasing surface drag by the same amount.

Since $\gamma$ is just the slope of the Clausius-Clapeyron relationship, it has a quasi-exponential dependence on temperature and thus may be expected to vary sharply across the range of observed terrestrial temperature conditions. One consequence of this dependence is that the CR may be expected to become more asymmetric with warming, as higher values of the slope imply a larger change in $E_{\mathrm{p}}$ for a given change in $E$. In turn, this may have implications for the strength of the coupling between the land surface and atmosphere in a warming climate. For example, recent work by Dirmeyer et al. $(2012,2013,2014)$ points to increases in metrics of land-atmosphere coupling strength in a warming climate. In Sect. 5, we further explore the response of our prototype to a global warming scenario.

In contrast to the complementary relationship, the Budyko curve exhibits no apparent change in shape for these parameter variations. This shape invariance is unsurprising given that the Budyko curve is only a function of the aridity in$\operatorname{dex} \phi$, as can be seen directly in the analytic solution for the analytic solution for $\eta=2$ (Eq. 15) or by substituting the expression for runoff in Eq. (14). Thus, while $E, E_{\mathrm{p}}$, and $P$ vary in response to changing prototype parameters, their ratios are constrained to lie along a fixed Budyko curve. Yang et al. (2009) suggest such shape invariance is characteristic of the Budyko curve response to what they broadly term "climate conditions", as they note climate forcing at a particular location simply moves the system from one point along its characteristic Budyko curve to another. By contrast, Yang et al. (2009) show how different locations fall onto distinct Budyko curves as a result of land surface or landscape properties such as soil, vegetation cover, rooting depth, etc.

\subsection{Process intervention experiments}

Apart from considering the sensitivity of the CR relationship (or Budyko curves) to parameter values, we can also assess how the prototype solutions respond to alteration of a particular process or term in the governing equations. For the

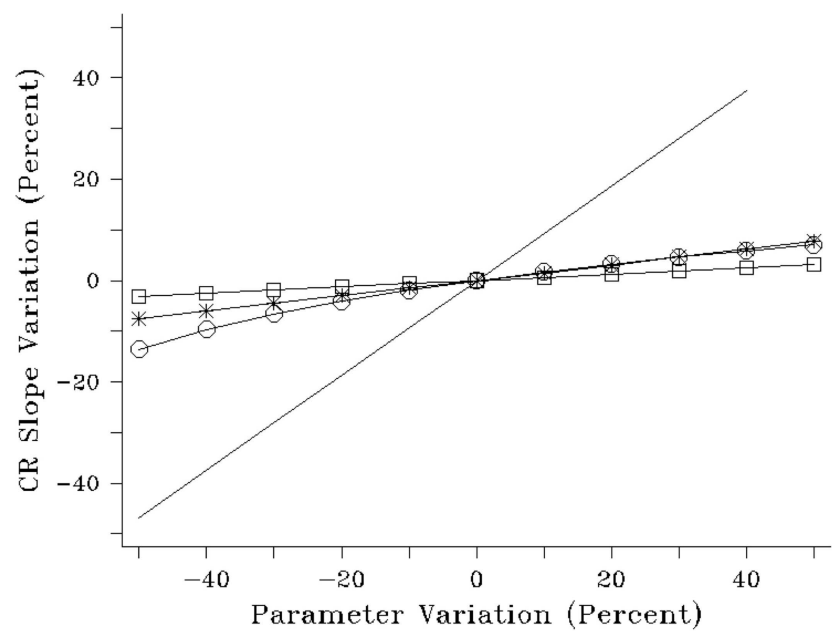

Figure 4. Parameter sensitivity of the complementary relationship slope. Results shown are for varying the slope of the saturationspecific humidity with respect to temperature (no symbols), surface drag coefficient (circles), surface cloud radiative forcing (stars), and convective adjustment timescale (squares).

first such intervention-type experiment, we alter the evapotranspiration ( $E$-intervention experiments) by prescribing as constant either (i) $\beta$ or (ii) $E_{\mathrm{p}} . E$-intervention experiment (i) is analogous to the methodology adopted in the Global Land Atmosphere Coupling Experiment (GLACE) type studies for comparing simulations with and without interactive soil moisture (Koster et al., 2004, 2006; Seneviratne et al., 2006). $E$-intervention experiment (ii) is similar to the approach Lintner et al. (2013) used to sever the feedback of near-surface climate onto $E_{\mathrm{p}}$, which here is mediated principally through suppression of the dependence of potential evapotranspiration on "atmospheric drying power", since the variation of radiative forcing across the prototype transect in its baseline configuration is weak (see discussion below).

Rather than present the complementary relationship for the $E$-intervention experiments (since the CR necessarily breaks down in either case), we instead show $T_{\mathrm{S}}$ and $q$ as functions of $w$ (Fig. 5a and b, respectively). For $E$-intervention experiment (i) with $\beta$ prescribed, the variation in $T_{\mathrm{s}}$ across soil moisture conditions (gray curve) is considerably reduced: while the difference in the baseline $T_{\mathrm{s}}$ (black curve) between the driest and wettest conditions is roughly $5 \mathrm{~K}$, it is under $0.5 \mathrm{~K}$ with $\beta$ prescribed. Similarly, the range of variation in specific humidity (here scaled to its surface value) across soil moisture states is attenuated relative to the baseline, although it is less pronounced than for surface temperature. Qualitatively opposite behavior is seen under $E$-intervention experiment (ii) with $E_{\mathrm{p}}$ prescribed, as the variations of both $T_{\mathrm{s}}$ and $q$ across the range $w$ are increased relative to their baseline values. Note that at low soil moisture, the behavior of the baseline case more closely resembles $E_{\mathrm{p}}$ prescribed experiments, while at high soil moisture, it is more similar to the $\beta$ prescribed experiment. 

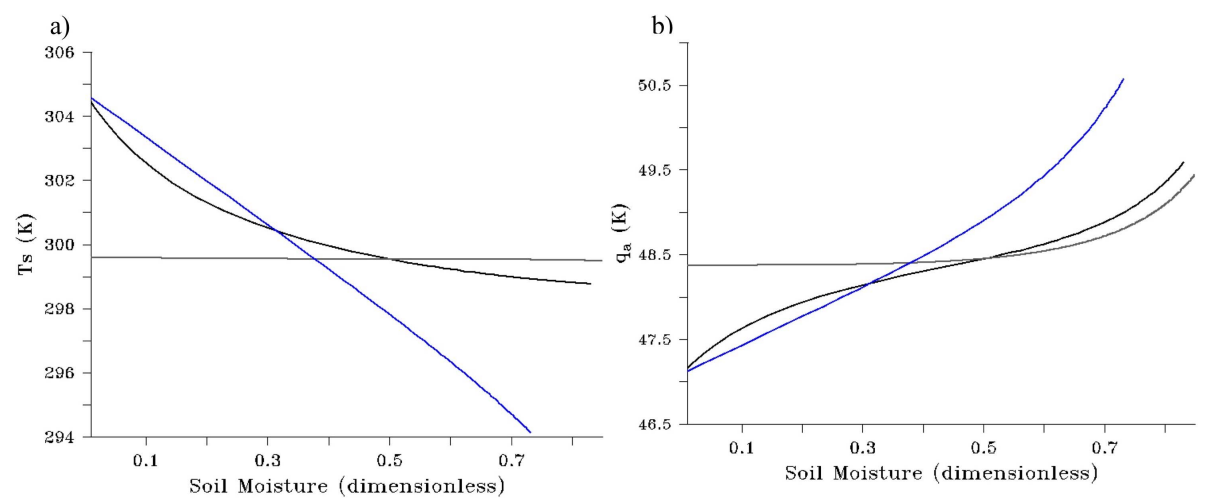

Figure 5. Comparison of prototype (a) surface temperature $T_{\mathrm{S}}$ and (b) surface air humidity $q_{\mathrm{a}}$ for the baseline (black), fixed $\beta$ (gray), and fixed $E_{\mathrm{p}}$ (blue) configurations of the prototype. Note that $q_{\mathrm{a}}$ is converted to temperature units of $\mathrm{K}$.
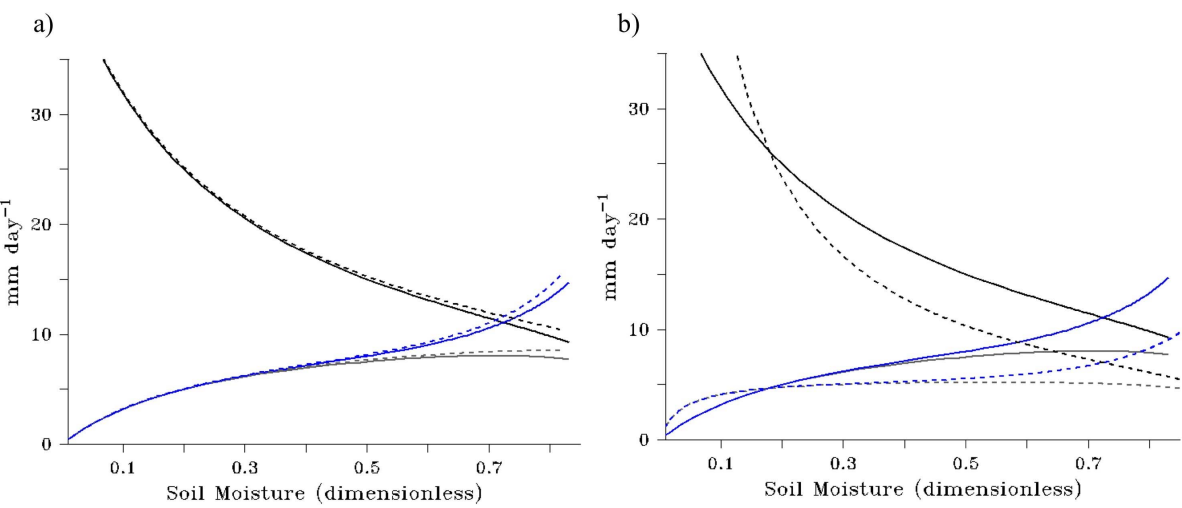

Figure 6. Impact on the complementary relationship from prescribing either (a) net surface radiative heating or (b) sensible heat flux. The curves depicted correspond to $E_{\mathrm{p}}$ (black), $E$ (gray), and $P$ (blue) for the baseline configuration (solid) and prescribed radiative or sensible heat fluxes (dashed).

We can further assess how the CR changes with intervention in either surface sensible heat $H$ or surface radiative heating $R_{\mathrm{S}}$, by prescribing either of these fluxes to a constant value. Under $R_{\mathrm{S}}$ intervention (Fig. 6a), there is little net change in the CR relative to the baseline over most of the range of soil moisture; however, at high $w$, both $E_{\mathrm{p}}$ and $E$ are slightly increased. The increase in $E_{\mathrm{p}}$ arises through a slight elevation of surface radiation heating above the baseline state, since the negative effect of cloud shortwave forcing, i.e., more convective clouds leading to less surface shortwave heating, is absent. This in turn feeds back onto precipitation, which is slightly enhanced. We further mention a competing effect, namely increased surface longwave forcing (and hence warming) with increased water vapor and convective cloudiness. For the parameter values chosen, this effect loses out to the shortwave forcing. On the other hand, uncertainty in these parameter values, particularly the cloud forcing, could alter the balance of these two effects.

Under $H$ intervention (Fig. 6b), the CR is dramatically altered, as $E_{\mathrm{p}}$ drops off more rapidly with increasing soil moisture, while $E$ rises faster at low soil moisture and then flat- tens off. The quantitative details of the change in shape of $E_{\mathrm{p}}$ and $E$ depend on the value of the sensible heat flux prescribed. Plotting $E_{\mathrm{p}}$ vs. $E$ (not shown) yields a best fit linear regressive slope of $\sim 28$, consistent with the very asymmetric nature of the $\mathrm{CR}$ when the variation in $H$ across the transect is suppressed.

\section{Impacts of global warming and large-scale irrigation}

\subsection{Global warming}

How the hydrologic cycle responds to global warming is clearly of great significance to projecting climate change impacts (Allen and Ingram, 2002; Milly et al., 2005). At present, our understanding of the hydrologic cycle response to warming is guided by some theoretical constraints; e.g., the Clausius-Clapeyron relationship promotes enhanced tropospheric moistening, although model projections show considerable spread in the regional signatures of hydrologic cycle change (Held and Soden, 2006; Neelin et al., 2006). Assessing global warming impacts on the terrestrial hydrologic 
cycle is complicated by changes in land use such as deforestation and agricultural conversion and coupling to vegetation (Lee et al., 2011).

Over the latter half of the twentieth century, several studies have reported widespread decreases in pan evaporation (Lawrimore and Peterson, 2000; Hobbins et al., 2004; Roderick and Farquhar, 2004; Shen et al., 2009), which can be related to $E_{\mathrm{p}}$. Several hypotheses have been proposed to explain the decreasing trend in pan evaporation, including increasing precipitation reducing the vapor pressure deficit of the lower atmosphere, global dimming reducing shortwave radiative heating at the surface, and stilling of surface winds reducing the exchange coefficient. Van Heerwaarden et al. (2010) conducted an extensive set of sensitivity tests for each of these effects on the CR using a conceptual model of the diurnal terrestrial boundary layer. They concluded that "except over wet soils, the actual evapotranspiration is more sensitive to changes in soil moisture than to changes in short wave radiation so that global evaporation should have increased. Nevertheless, Wild et al. (2004) speculate that in the latter half of the 20th century, increased moisture transport from the oceans enhanced precipitation over land, but suppressed the evaporation - opposite to [their] expectations".

Figure 7 depicts the effect on prototype hydroclimate of imposing a $2 \mathrm{~K}$ warming of the prescribed column-mean temperature. In this figure, differences between the $2 \mathrm{~K}$ warming configuration and the baseline are plotted against baseline values of $w$; also shown is the difference in soil moisture between the $2 \mathrm{~K}$ warming and baseline scenarios. Across the range of baseline soil moisture conditions, the imposed warming decreases $E_{\mathrm{p}}$ (black), since $q$ itself increases. While $E$ (gray) increases with warming at $w$, it decreases for $w>0.5$, which is consistent with the results of van Heerwaarden et al. (2010). In addition, $P$ (blue) increases under warming over the entire range of precipitation values (similar to Wild et al., 2004), albeit with a local minimum at intermediate soil moisture values.

The opposing changes of $E_{\mathrm{p}}$ and $E$ with warming at low soil moisture are consistent with expectations from the CR, as an increase in one corresponds to a decrease in the other. Of course, increasing the temperature increases the value of $\gamma$, which means the slope of the CR increases between the baseline and $2 \mathrm{~K}$ warming scenarios. On the other hand, since $E_{\text {wet }}$ decreases with tropospheric warming, both $E_{\mathrm{p}}$ and $E$ follow the behavior of $E_{\text {wet }}$ and therefore decrease.

While the values of hydroclimatic variables may change substantially between the baseline and $2 \mathrm{~K}$ warming scenarios, the Budyko curve is unaltered, as discussed in Sect. 4.1. However, as Fig. 8 illustrates, forcing conditions, i.e., the value of drying advection, identified with specific points along the Budyko curve in the baseline scenario are shifted to lower values of the aridity index $\phi$ in the $2 \mathrm{~K}$ warming scenario, since $E_{\mathrm{p}}$ decreases while $P$ increases. Based on these results, we note the potential utility of the Budyko curve in

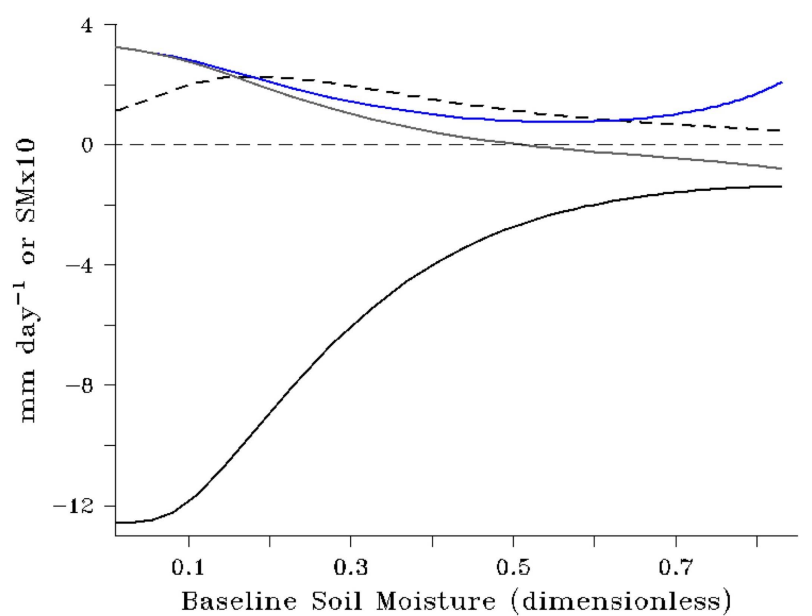

Figure 7. Differences in $E_{\mathrm{p}}$ (black), $E$ (gray), and $P$ (blue) for a $+2 \mathrm{~K}$ warming relative to the baseline configuration as functions of soil moisture in the baseline configuration. Also shown is the difference in soil moisture (dashed black), which has been rescaled by a factor of 10 .

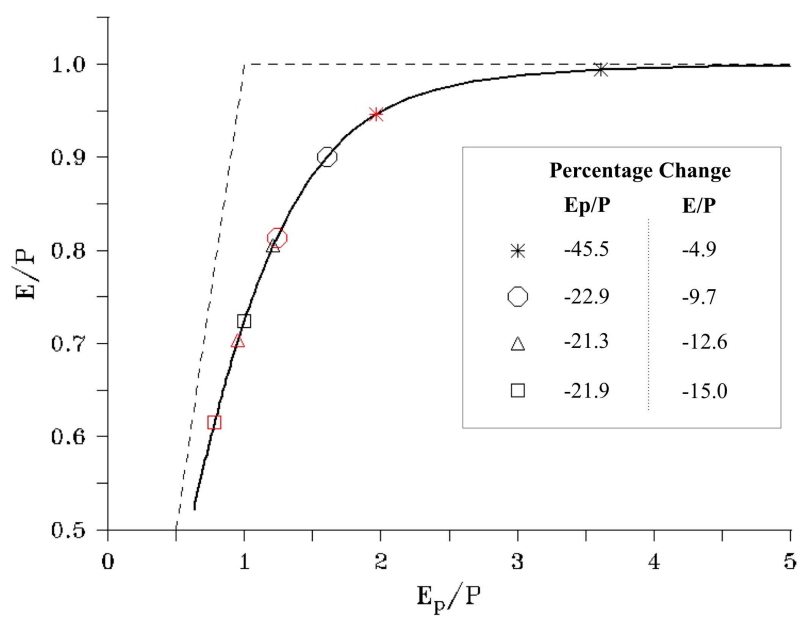

Figure 8. Shift in selected points along the Budyko curve for the baseline (black symbols) and $+2 \mathrm{~K}$ warming (red) configuration. Pairs of like-shaped symbols correspond to the same level of imposed drying advection forcing. The values shown in the inset are the percentage changes for each of the baseline and $+2 \mathrm{~K}$ warming pairs.

providing qualitative or even quantitative constraints on how terrestrial hydroclimate variables will respond to warming.

\subsection{Large-scale irrigation}

Over many parts of the world, irrigation has been adopted to support agricultural production. Over India, for example, irrigation is now sufficiently extensive that large-scale alterations of hydroclimate may be occurring (Cook et al., 2010; Guimberteau et al., 2011). With respect to potential irrigation-induced changes in hydroclimate, Ozdogan et 

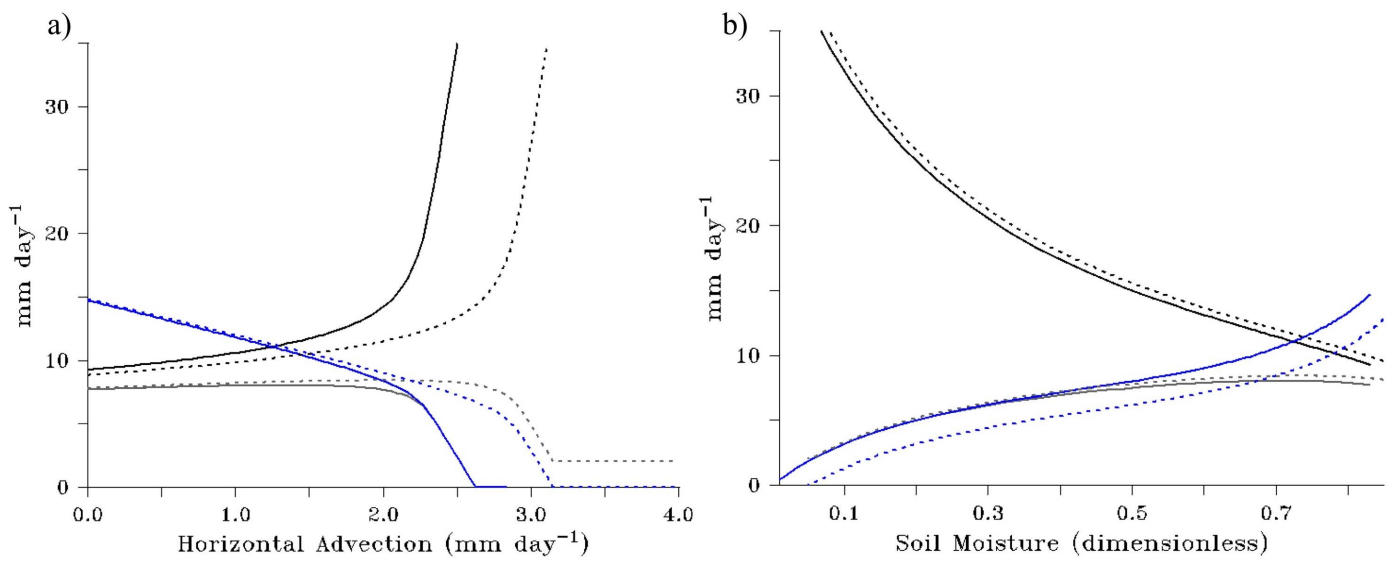

Figure 9. Large-scale irrigation impacts on prototype hydroclimate. (a) $E_{\mathrm{p}}$ (black), $E$ (gray), and $P$ (blue) for the baseline (solid curves) and $I=2 \mathrm{~mm} \mathrm{day}^{-1}$ large-scale irrigation scenario (dotted curves), plotted with respect to horizontal moisture advection, scaled to units of $\mathrm{mm} \mathrm{day}^{-1}$. Here, horizontal advection values correspond to drying advection, which are associated with decreasing precipitation. (b) As in (a) but with soil moisture as the abscissa.

al. (2006) employed a mesoscale climate model and field data to demonstrate that large-scale irrigation in southeastern Turkey has impacted evaporation and potential evaporation in a complementary manner. They found a variety of interactions responsible for the trends, including increased atmospheric stability, decreased vapor pressure deficit, and, interestingly, a strong decrease in wind speed. Han et al. (2014) point out that while trends in $E_{\mathrm{p}}$ have often been invoked to estimate possible trends in $E$, how irrigation may impact $E_{\mathrm{p}}$ has typically been neglected in the assessment and interpretation of $E_{\mathrm{p}}$ trends. It is thus worth briefly investigating how large-scale irrigation modulates the Budyko and complementary relationships within the framework of the prototype analyzed here. To do this, we consider the addition of an irrigation source, $I$, to the soil moisture balance Eq. (6), which then becomes $P+I=E+Q_{\text {runoff }}$.

To see the impact of irrigation on the prototype hydroclimate, Fig. 9 depicts $E, E_{\mathrm{p}}$, and $P$ in the baseline and $I=2 \mathrm{~mm}$ day $^{-1}$ configurations. Here, we have plotted these quantities with respect to both horizontal dry advection (Fig. 9a) and soil moisture (Fig. 9b). Given the direct moistening of the atmosphere by irrigation, the transition between nonprecipitating and precipitating conditions in the presence of irrigation occurs at a significantly larger value of drying advection in the large-scale irrigation scenario, as shown in Fig. 9a. Across the range of moisture advection values, both $E$ and $P$ are enhanced in the presence of large-scale irrigation, as expected, and $E_{\mathrm{p}}$ decreases, in line with complementarity. Additionally, at low to intermediate precipitation, $E$ exceeds $P$. Thus, whatever soil moisture is not locally recycled as precipitation would instead be transported downwind, as suggested by some studies on observed irrigation (e.g., DeAngelis et al., 2010). Viewed with respect to soil moisture (Fig. 9b), the inclusion of large-scale irrigation is seen to induce a slight increase in $E$ for a given value of $w$. On the other hand, since the value of drying advection is larger at a given $w$ in the presence of irrigation, $E_{\mathrm{p}}$ itself is larger. Directly relating $E_{\mathrm{p}}$ to $E$ indicates effectively no change in the slope of the CR, though the intercept is increased when irrigation is applied (not shown). Precipitation at a given value of $w$ is lowered in the irrigated scenario.

As a consequence of the changes in $E$ and $P$, the Budyko curve for irrigated conditions (Fig. 10, dotted line) is shifted above its baseline: in fact, the irrigated Budyko curve extends above 1 for $\phi>1$, as water limitation is effectively alleviated with the imposed irrigation water source. When $E$ is replaced by the residual $E^{*}=E-I$, the resulting Budyko-like curve (stars) drops below the baseline.

Of course, we should point out that by imposing irrigation in the prototype with tropospheric temperature prescribed, we are neglecting a potentially important cooling of the lowermost atmosphere, not to mention that our prototype does not account for changes in convective initiation or triggering that may occur, e.g., through changes to atmospheric stability (Findell et al., 2011). Moreover, we do not take into account vegetation control on $E$ since we only represent soil moisture dependence of evapotranspiration through a bucket model. Thus, the irrigation impacts described here merely reflect the direct effect of added moisture to the atmosphere.

\section{Summary and conclusions}

In this study, we use an idealized prototype incorporating the key physics of large-scale land-atmosphere coupling to derive analytic expressions for the well-known Budyko and complementary relationships. Our approach differs from previous analytic approaches in that precipitation and moisture convergence are treated implicitly rather than applied as an external forcing. The analytic solutions permit straightfor- 


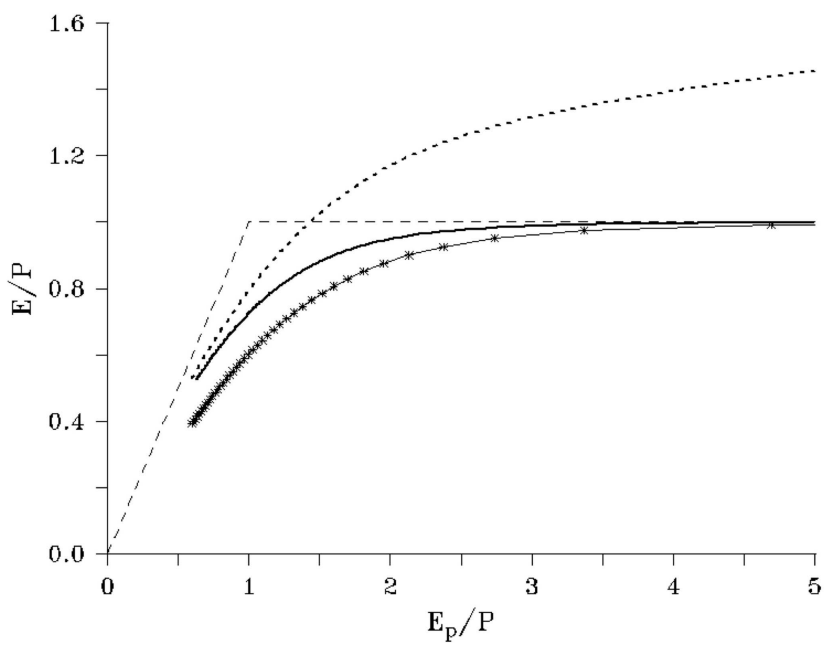

Figure 10. Comparison of Budyko curves for the baseline (solid) and $I=2 \mathrm{mmday}^{-1}$ (dotted) configurations. Also shown is a Budyko-like curve in which $E$ is replaced by $E^{*}=E-I$ (stars).

ward diagnosis of the sensitivity of the Budyko and complementary relationships to atmospheric and land surface parameters. In particular, the slope of the $\mathrm{CR}$ is shown to be mostly dependent on the temperature, with important implications for the continental hydrologic cycle with a warming climate. One consequence of this dependence is that the CR may be expected to become more asymmetric with warming, as higher values of the slope imply a larger change in potential evaporation for a given change in evapotranspiration. On the other hand, the Budyko curve is very stable to many parameterizations of the model parameters or global temperature. It is thus expected that the Budyko curve should remain relatively stable under a warming climate. Other causes of anthropogenic changes such as large-scale irrigation are however shown to strongly impact the Budyko curve, with little impact on the CR.

Acknowledgements. This work was supported by National Science Foundation (NSF) grant AGS-1035968 and New Jersey Agricultural Experiment Station Hatch grant NJ07102.

Edited by: V. Andréassian

\section{References}

Allen, M. R. and Ingram, W. J.: Constraints on future changes in climate and the hydrologic cycle, Nature, 419, 224-232, doi:10.1038/nature01092, 2002.

Betts, A. K.: Coupling of water vapor convergence, clouds, precipitation, and land-surface processes, J. Geophys. Res., 112, D10108, doi:10.1029/2006JD008191, 2007.

Betts, A. K. and Miller, M. J.: A new convective adjustment scheme. Part II: Single column tests using GATE wave, BOMEX, ATEX and arctic air-mass data sets, Q. J. Roy. Meteor. Soc., 112, 693709, doi:10.1002/qj.49711247308, 1986.

Betts, A. K. and Viterbo, P.: Land-surface, boundary layer, and cloud-field coupling over the southwestern Amazon in ERA40, J. Geophys. Res., 110, D14108, doi:10.1029/2004JD005702, 2005.

Betts, A. K., Ball, J., Beljaars, A., Miller, M. J., and Viterbo, P.: The land surface-atmosphere interaction: a review based on observational and global modeling perspectives, J. Geophys. Res., 101, 7209-7225, doi:10.1029/95JD02135, 1996.

Betts, A. K., Ball, J. H., Bosilovich, M., Viterbo, P., and Zhang, Y.: Intercomparison of water and energy budgets for five Mississippi subbasins between ECMWF reanalysis (ERA-40) and NASA Data Assimilation Office GCM for 1990, J. Geophys. Res., 108, 8618, doi:10.1029/2002JD003127, 2003.

Betts, A. K., Desjardins, R., Worth, D., Wang, S., and Li, J.: Coupling of winter climate transitions to snow and clouds over the Prairies, J. Geophys. Res.-Atmos., 119, 1118-1139, doi:10.1002/2013JD021168, 2014.

Bosman, H. H.: The influence of installation practices on evaporation from Symon's tank and American Class A-pan evaporimeters, Agr. Forest Meteorol., 41, 307-323, 1987.

Bouchet, R.: Evapotranspiration reelle et potentielle, signification climatique, IAHS Publ., 62, 134-142, 1963 (in French).

Brutsaert, W. and Parlange, M. B.: Hydrologic cycle explains the evaporation paradox, Nature, 396, 29-30, 1998.

Brutsaert, W. and Stricker, H.: An advection-aridity approach to estimate actual regional evapotranspiration, Water Resour. Res., 15, 443-450, 1979.

Budyko, M. I.: The heat and water balance of the Earth's surface, the general theory of physical geography and the problem of the transformation of nature, Sov. Geogr., 2, 3-12, doi:10.1080/00385417.1961.10770737, 1961.

Budyko, M. I.: Climate and Life, Academic Press, Orlando, FL, 508 pp., 1974.

Cook, B. I., Puma, M. J., and Krakauer, N. Y.: Irrigation induced surface cooling in the context of modern and increased greenhouse gas forcing, Clim. Dynam., 37, 1587-1600, doi:10.1007/s00382-010-0932-x, 2010.

Crago, R. and Crowley, R.: Complementary relationships for near-instantaneous evaporation, J. Hydrol., 300, 199-211, doi:10.1016/j.jhydrol.2004.06.002, 2005.

DeAngelis, A., Dominguez, F., Fan, Y., Robock, A., Kustu, M. D., and Robinson, D.: Evidence of enhanced precipitation due to irrigation over the Great Plains of the United States, J. Geophys. Res., 115, D15115, doi:10.1029/2010JD013892, 2010.

Dirmeyer, P. A., Cash, B. A., Kinter III, J. L., Stan, C., Jung, T., Marx, L., Towers, P., Wedi, N., Adams, J. M., Altshuler, E. L., Huang, B., Jin, E. K., and Manganello, J.: Evidence for enhanced land-atmosphere feedback in a warming climate, J. Hydrometeorol., 13, 981-995, doi:10.1175/JHM-D-11-0104.1, 2012.

Dirmeyer, P. A., Jin, Y., Singh, B., and Yan, X.: Trends in landatmosphere interactions from CMIP5 simulations, J. Hydrometeor., 14, 829-849, doi:10.1175/JHM-D-12-0107.1, 2013.

Dirmeyer, P. A., Wang, Z., Mbuh, M. J., and Norton, H. E.: Intensified land surface control on boundary layer growth in a changing climate, Geophys. Res. Lett., 41, W04403, doi:10.1002/2013GL058826, 2014. 
Donohue, R. J., Roderick, M. L., and McVicar, T. R.: On the importance of including veg30 etation dynamics in Budyko's hydrological model, Hydrol. Earth Syst. Sci., 11, 983-995, doi:10.5194/hess-11-983-2007, 2007.

Eagleson, P.: Climate, soil, and vegetation, 2. The distribution of annual precipitation derived from observed storm sequences, Water Resour Res., 14, 713-721, 1978a.

Eagleson, P.: Climate, soil, and vegetation, 6. Dynamics of the annual water balance, Water Resour. Res., 14, 749-764, 1978b.

Eagleson, P.: Climate, soil, and vegetation, 1. Introduction to water balance dynamics, Water Resour. Res., 14, 705-712, 1978c.

Findell, K. L., Gentine, P., Lintner, B. R., and Kerr, C.: Probability of afternoon precipitation in eastern US and Mexico enhanced by high evaporationm, Nat. Geosci., 4, 434-439, doi:10.1038/ngeo1174, 2011.

$\mathrm{Fu}$, B. P.: On the calculation of the evaporation from land surface, Sci. Atmos. Sin, 5, 23-31, 1981.

Gentine, P., Entekhabi, D. D., and Polcher, J.: The diurnal behavior of evaporative fraction in the soil-vegetation-atmospheric boundary layer continuum, J. Hydrometeorol., 12, 1530-1546, doi:10.1175/2011JHM1261.1, 2011.

Gentine, P., D'Odorico, P., Lintner, B. R., Sivandran, G., and Salvucci, G.: Interdependence of climate, soil, and vegetation as constrained by the Budyko curve. Geophys. Res. Lett., 39, L19404, doi:10.1029/2012GL053492, 2012.

Gerrits, A. M. J., Savenije, H. H. G., Veling, E. J. M., and Pfister, L.: Analytical derivation of the Budyko curve based on rainfall characteristics and a simple evaporation model, Water Resour. Res., 45, W04403, doi:10.1029/2008WR007308, 2009.

Granger, R. J.: A complementary relationship approach for evaporation from nonsaturated surfaces, J. Hydrol., 111, 31-38, 1989.

Guimberteau, M., Laval, K., Perrier, A., and Polcher, J.: Global effect of irrigation and its impact on the onset of the Indian summer monsoon, Clim. Dynam., 39, 1329-1348, doi:10.1007/s00382011-1252-5, 2011.

Han, S., Tang, Q., Xu, D., and Wang, S.: Irrigation-induced changes in potential evaporation: more attention is needed, Hydrol. Process., 28, 2717-2720, doi:10.1002/hyp.10108, 2014.

Harman, C. J., Troch, P. A., and Sivapalan, M.: Functional model of water balance variability at the catchment scale: 2 . Elasticity of fast and slow runoff components to precipitation change in the continental United States, Water Resour. Res., 47, W02523, doi:10.1029/2010WR009656, 2011.

Held, I. M. and Soden, B. J.: Robust response of the hydrological cycle to global warming, J. Climate, 19, 5686-5699, 2006.

Hobbins, M. T., Ramirez, J. A., Brown, T. C., and Claessens, L. H. J. M.: The complementary relationship in estimation of regional evapotranspiration: the complementary relationship area evapotranspiration and advection-aridity models, Water Resour. Res., 37, 1367-1387, 2001.

Hobbins, M. T., Ramirez, J. A., and Brown, T. C.: Trends in pan evaporation and actual evapotranspiration across the conterminous US: paradoxical or complementary?, Geophys. Res. Lett., 31, L13503, doi:10.1029/2004GL019846, 2004.

Istanbulluoglu, E., Wang, T., Wright, O. M., and Lenters, J. D.: Interpretation of hydrologic trends from a water balance perspective: the role of groundwater storage in the Budyko hypothesis, Water Resour. Res., 48, W00H16, doi:10.1029/2010WR010100, 2012.
Kahler, D. M. and Brutsaert, W.: Complementary relationship between daily evaporation in the environment and pan evaporation, Water Resour. Res., 42, W05413, doi:10.1029/2005WR004541, 2006.

Koster, R. and Suarez, M.: A simple framework for examining the interannual variability of land surface moisture fluxes, J. Climate, 12, 1911-1917, 1999.

Koster, R. D., Dirmeyer, P. A., Guo, Z., Bonan, G., Chan, E., Cox, P., Davies, H., Gordon, T., Kanae, S., Kowalczyk, E., Lawrence, D., Liu, P., Lu, S., Malyshev, S., McAvaney, B., Mitchell, K., Oki, T., Oleson, K., Pitman, A., Sud, Y., Taylor, C., Verseghy, D., Vasic, R., Xue, Y., and Yamada, T.: Regions of strong coupling between soil moisture and precipitation, Science, 305, 11381140, 2004.

Koster, R. D., Guo, Z., Dirmeyer, P. A., Bonan, G., Chan, E., Cox, P., Davies, H., Gordon, T., Kanae, S., Kowalczyk, E., Lawrence, D., Liu, P., Lu, S., Malyshev, S., McAvaney, B., Mitchell, K., Oki, T., Oleson, K., Pitman, A., Sud, Y., Taylor, C., Verseghy, D., Vasic, R., Xue, Y., and Yamada, T.: GLACE: the Global LandAtmosphere Coupling Experiment, Part I: Overview, J. Hydrometeorol., 7, 590-610, 2006.

Kirchner, J. W.: Catchments as simple dynamical systems: catchment characterization, rainfall-runoff modeling, and doing hydrology backward, Water Resour. Res., 45, W02429, doi:10.1029/2008WR006912, 2009.

Lawrimore, J. and Peterson, T.: Pan evaporation trends in dry and humid regions of the United States, J. Hydrometeorol., 1, 543$546,2000$.

Lee, J.-E., Lintner, B. R., Boyce, C. K., and Lawrence, P. J.: Land use change exacerbates tropical South American drought by sea surface temperature variability, Geophys. Res. Lett., 38, L19706, doi:10.1029/2011GL049066, 2011.

Lettau, H.: Evapotranspiration climatonomy, I. A new approach to numerical prediction of monthly evapotranspiration, runoff, and soil moisture storage, Mon. Weather Rev., 97, 691-699, 1969.

L'homme, J. and Guilioni, L.: Comments on some articles about the complementary relationship, J. Hydrol., 323, 1-3, doi:10.1016/j.jhydrol.2005.08.014, 2006.

Lintner, B. R., Gentine, P., Findell, K. L., D’Andrea, F., Sobel, A. H., and Salvucci, G. D.: An idealized prototype for largescale land-atmosphere coupling, J. Climate, 26, 2379-2389, doi:10.1175/JCLI-D-11-00561.1, 2013.

Milly, P. C. D.: Climate, soil water storage, and the average annual water balance, Water Resour. Res., 30, 2143-2156, 1994.

Milly, P. C. D. and Dunne, K.: Macroscale water fluxes - 2. Water and energy supply control of their interannual variability, Water Resour. Res., 38, 1206, doi:10.1029/2001WR000760, 2002.

Milly, P. C. D., Dunne, K., and Vecchia, A. V.: Global pattern of trends in streamflow and water availability in a changing climate, Nature, 438, 347-350, doi:10.1038/nature04312, 2005.

Morton, F. I.: Operational estimates of areal evapotranspiration and their significance to the science and practice of hydrology, J. Hydrol., 66, 1-76, 1983.

Neelin, J. D. and Zeng, N.: A quasi-equilibrium tropical circulation model-formulation, J. Atmos. Sci., 57, 1741-1766, 2000.

Neelin, J. D., Munnich, M., Su, H., Meyerson, J., and Holloway, C.: Tropical drying trends in global warming models and observations, P. Natl. Acad. Sci. USA, 103, 6110-6115, 2006. 
Ozdogan, M., Salvucci, G., and Anderson, B.: Examination of the Bouchet-Morton complementary relationship using a mesoscale climate model and observations under a progressive irrigation scenario, J. Hydrometeorol., 7, 235-251, 2006.

Pettijohn, J. C. and Salvucci, G. D.: A new two-dimensional physical basis for the complementary relation between terrestrial and pan evaporation, J. Hydrometeorol., 10, 565-574, doi:10.1175/2008JHM1026.1, 2009.

Porporato, A., Laio, F., Ridolfi, L., and Rodríguez-Iturbe, I.: Plants in water-controlled ecosystems: active role in hydrologic processes and response to water stress - III. Vegetation water stress, Adv. Water Resour., 24, 725-744, 2001.

Porporato, A., Daly, E., and Rodríguez-Iturbe, I.: Soil water balance and ecosystem response to climate change, Am. Nat., 164, 625632, 2004.

Potter, N., Zhang, L., Milly, P., McMahon, T., and Jakeman, A.: Effects of rainfall seasonality and soil moisture capacity on mean annual water balance for Australian catchments, Water Resour. Res., 41, W06007, doi:10.1029/2004WR003697, 2005.

Priestley, C. H. B. and Taylor, R. J.: On the assessment of surface heat flux and evaporation using large-scale parameters, Mon. Weather Rev., 100, 81-88, 1972.

Ramirez, J. A., Hobbins, M. T., and Brown, T. C.: Observational evidence of the complementary relationship in regional evaporation lends strong support for Bouchet's hypothesis, Geophys. Res. Lett., 32, L15401, doi:10.1029/2005GL023549, 2005.

Roderick, M. L. and Farquhar, G. D.: Changes in Australian pan evaporation from 1970 to 2002, Int. J. Climatol., 24, 1077-1090, doi:10.1002/joc.1061, 2004.

Roderick, M. L. and Farquhar, G. D.: A simple framework for relating variations in runoff to variations in climatic conditions and catchment properties, Water Resour. Res., 47, W00G07, doi:10.1029/2010WR009826, 2011.

Seneviratne, S. I., Koster, R. D., Guo, Z., Dirmeyer, P. A., Kowalczyk, E., Lawrence, D., Liu, P., Lu, C.-H., Mocko, D., Oleson, K. W., and Verseghy, D.: Soil moisture memory in AGCM simulations: analysis of Global Land-Atmosphere Coupling Experiment (GLACE) data, J. Hydrometeorol., 7, 1090-1112, 2006.

Shen, Y., Liu, C., Liu, M., Zeng, Y., and Tian, C.: Change in pan evaporation over the past 50 years in the arid region of China, Hydrol. Process., 24, 225-231, doi:10.1002/hyp.7435, 2009.

Sherwood, S. and Fu, Q.: A drier future?, Science, 343, 737-739, doi:10.1126/science.1247620, 2014.

Sivapalan, M., Yaeger, M. A., Harman, C. J., Xu, X., and Troch, P. A.: Functional model of water balance variability at the catchment scale: 1. Evidence of hydrologic similarity and space- time symmetry, Water Resour. Res., 47, W02522, doi:10.1029/2010WR009568, 2011.

Sobel, A. H. and Bretherton, C. S.: Modeling tropical precipitation in a single column, J. Climate, 13, 4378-4392, 2000.

Sobel, A. H., Nilsson, J., and Polvani, L.: The weak temperature gradient approximation and balanced tropical moisture waves, J. Atmos. Sci., 58, 3650-3665, 2001.

Szilagyi, J.: On Bouchet's complementary hypothesis, J. Hydrol., 246, 155-158, 2001.

Szilagyi, J.: On the inherent asymmetric nature of the complementary relationship of evaporation, Geophys. Res. Lett., 34, L02405, doi:10.1029/2006GL028708, 2007.
Szilagyi, J. and Jozsa, J.: Complementary relationship of evaporation and the mean annual water-energy balance, Water Resour. Res., 45, W09201, doi:10.1029/2009WR008129, 2009.

Troch, P. A., Martinez, G. F., Pauwels, V. R. N., Durcik, M., Sivapalan, M., Harman, C., Brooks, P. D., Gupta, H., and Huxman, T.: Climate and vegetation water use efficiency at catchment scales, Hydrol. Process., 23, 24090-2414, doi:10.1002/hyp.7358, 2009.

Tuttle, S. E. and Salvucci, G. D.: A new method for calibrating a simple, watershed-scale model of evapotranspiration: maximizing the correlation between observed streamflow and modelinferred storage, Water Resour. Res., 48, W05556, doi:10.1029/2011WR011189, 2012.

van Heerwaarden, C. C., Vilà-Guerau de Arellano, J., and Teuling, A. J.: Land-atmosphere coupling explains the link between pan evaporation and actual evapotranspiration trends in a changing climate, Geophys. Res. Lett., 37, L21401, doi:10.1029/2010GL045374, 2010.

Wild, M., Ohmura, A., Gilgen, H., and Rosenfeld, D.: On the consistency of trends in radiation and temperature records and implications for the global hydrological cycle, Geophys. Res. Lett., 31, L11201, doi:10.1029/2003GL019188, 2004.

Williams, C. A., Reichstein, M., Buchmann, N., Baldocchi, D., Beer, C., Schwalm, C., Wohlfahrt, G., Hasler, N., Bernhofer, C., Foken, T., Papale, D., Schymanski, S., and Schaefer, K. Climate and vegetation controls on the surface water balance: synthesis of evapotranspiration measured across a global network of flux towers, Water Resour. Res., 48, W06523, doi:10.1029/2011WR011586, 2012.

Yang, D., Sun, F., Liu, Z., Cong, Z., Ni, G., and Lei, Z.: Analyzing spatial and temporal variability of annual water-energy balance in nonhumid regions of China using the Budyko hypothesis, Water Resour. Res., 43, W04426, doi:10.1029/2006WR005224, 2007.

Yang, D., Shao, W., Yeh, P. J.-F., Yang, H., Kanae, S., and Oki, T.: Impact of vegetation cover age on regional water balance in the nonhumid regions of China, Water Resour. Res., 45, W00A14, doi:10.1029/2008WR006948, 2009.

Yang, H., Yang, D., Lei, Z., and Sun, F.: New analytical derivation of the mean annual waterenergy balance equation, Water Resour. Res., 44, W03410, doi:10.1029/2007WR006135, 2008.

Zanardo, S., Harman, C. J., Troch, P. A., Rao, P. S. C., and Sivapalan, M.: Intra-annual rainfall variability control on interannual variability of catchment water balance: a stochastic analysis, Water Resour. Res., 48, W00J16, doi:10.1029/2010WR009869, 2012.

Zeng, N., Neelin, J. D., and Chou, C.: A quasi-equilibrium tropical circulation model-implementation and simulation, J. Atmos. Sci., 57, 1767-1796, 2000.

Zhang, L., Hickel, K., Dawes, W., Chiew, F., Western, A., and Briggs, P.: A rational function approach for estimating mean annual evapotranspiration, Water Resour. Res., 40, W02502, doi:10.1029/2003WR002710, 2004. 